\title{
ПРАКТИКИ ОРИЕНТИРОВАНИЯ И САМОСТОЯТЕЛЬНОГО ПЕРЕДВИЖЕНИЯ НЕЗРЯЧИХ ЛЮДЕЙ В ГОРОДСКОЙ СРЕДЕ
}

\begin{abstract}
В 2021 г. исполняется десять лет с начала реализации федеральной программы «Доступная среда». Следуя Конвенции ООН о правах инвалидов, ратифицированной несколькими годами ранее, программа стала первой масштабной попыткой преодоления отчуждающего эффекта публичных пространств российских городов. На сегодняшний день элементы инклюзивного проектирования жилых построек и публичных пространств стали нормой градостроительной практики. Однако доступность российских городов оценивается неоднозначно. Тогда как официальная отчётность свидетельствует об увеличении доли доступных объектов, экспертные оценки (включая оценки самих инвалидов) выражают озабоченность отсутствием явных позитивных изменений. Статья обнаруживает ряд оснований такого несоответствия. Используя теоретические ресурсы феноменологии и этнометодологии, мы обращаемся к анализу повседневных перемещений незрячих горожан, описывая особенности их ориентации и навигации, а также барьеры, затрудняющие их самостоятельное передвижение. Ориентация незрячих горожан строится на выделении, картографировании и ситуативной верификации ими наиболее устойчивых ориентиров маршрута с помощью тактильной, вестибулярной, световой, обонятельной, аудиальной или интуитивной чувствительности. Самостоятельное перемещение незрячих по городу затрудняется отсутствием необходимого количества ориентиров (из-за изменчивости города или непредусмотренности) или
\end{abstract}

Виктор Вадимович Синицын- магистр социальных наук, стажёр-исследователь, Научноучебной лаборатории социальных исследований города, Национальный исследовательский университет «Высшая школа экономики», Москва, Россия. Электронная почта: viktor. sinitsyn@gmail.com

Оксана Николаевна Запорожец- к. социол. н., доцент Факультета городского и регионального развития, Национальный исследовательский университет «Высшая школа экономики», Москва, Россия. Электронная почта: ozaporozhets@hse.ru 
ошибочной интерпретацией таких знаков, обусловленной структурно или ситуативно. Препятствием для передвижения незрячих по городу становится не только состояние городской среды, но и страхи, связанные с рисками выхода в город, а также некомпетентная помощь, вмешательство в процесс навигации или противодействие других горожан. Проведенное исследование показывает, что программа «Доступная среда» сконцентрирована преимущественно на изменении городской материальности, однако самостоятельность освоения города незрячими связана с большим количеством предпосылок, среди которых способность к достоверной интерпретации окружения, коммуникации с другими горожанами, а также установки незрячих в отношении окружающих и городской среды. В заключение мы предлагаем ряд мер, позволяющих оптимизировать реализуемые программы городских изменений.

Ключевые слова: незрячие, инвалидность, городская среда, город, ориентация, доступность, феноменология, качественная социология

DOI: 10.17323/727-0634-2021-19-4-669-684

Согласно международным исследованиям, незрячие люди выходят из дома значительно реже по сравнению с людьми с сохранным зрением (Neuschmid et al. 2014). Несмотря на отсутствие сопоставимых данных можно предположить, что эта ситуация характерна и для России. Особенно остро вопрос ориентации незрячих людей встает в крупных городах - с их огромными пространствами, сложными маршрутами, большим скоплением людей, насыщенностью материальными объектами и технологиями, сенсорной интенсивностью городской жизни.

Трудность передвижения незрячих людей по городу, помимо прочего, связана с его окулоцентричностью- доминированием визуальности в системе городских ориентиров. Описывая формирование модерных городов, аналитики отмечали (Сеннет 2016), что подчинение городской планировки геометрической перспективе и увеличение масштабов города привело к тому, что визуальные знаки стали доминирующим способом разметки и ориентации современного мегаполиса. Кроме того, конкуренция за туристические потоки, инвестиции и лояльность жителей актуализировала важность позитивного и узнаваемого образа города, создаваемого как городскими репрезентациями, так и элементами городской среды-например, эстетикой городских публичных пространств (Kalyukin et al. 2015). Учитывая постоянно возрастающее значение визуальности в организации городской жизни, современные мегаполисы являются сравнительно неблагоприятной средой для незрячих людей.

Начиная с 1970-х гг. негативное влияние городской среды на тех, чья телесная организация или сенсорное восприятие значительно отличаются от условно «здорового» человека, признается и активно критикуется движениями за права людей с инвалидностью в Великобритании и США. 
Объединившиеся под лозунгом «Ничего для нас без нас» инвалиды и политические активисты выступили против сложившейся структуры медицинского, средового и культурного угнетения (Charlton 1998). Впоследствии совместные усилия людей с инвалидностью, учёных и политиков привели к признанию необходимости и разработке программ социальной и средовой инклюзии, включая значительные изменения городского пространства (Goodley 2017; Ferguson, Nusbaum 2012).

В России изменение городской среды связано с подписанием Конвенции ООН о правах инвалидов в 2008 г. Стартовавшая в 2011 г. федеральная программа «Доступная среда» стала первым опытом применения базовых положений Конвенции на практике (Ярская-Смирнова, Романов 2010). Несмотря на то, что в 2021 г. исполняется десять лет с начала реализации программы адаптации городского пространства для нужд людей с инвалидностью, её результаты оцениваются неоднозначно. В то время как официальная отчётность свидетельствует об увеличении количества доступных городских объектов, экспертные оценки, включая оценки исследователей и самих инвалидов, фиксируют отсутствие значительных изменений и содержат критику имеющихся программ (Сталингулаг 2019; Wylsacom 2018; Филлипс 2018; ДЭПиР г. Москвы 2018; Клепикова 2015; Наберушкина 2011).

Основываясь на анализе повседневных перемещений незрячих горожан, мы выясняем причины неоднозначной оценки реализуемых мер. Описывая специфику ориентации незрячих людей при помощи теоретических ресурсов феноменологии и этнометодологии, выявляем навыки незрячего человека и характеристики среды, обеспечивающие его самостоятельное передвижение по городу. Анализируя ситуации, обозначаемые информантами в качестве проблемных, выделяем характеристики среды и практики, затрудняющие их самостоятельную мобильность. Мы полагаем, что ориентация незрячего человека в городской среде является мультисенсорной и происходит в постоянном взаимодействии с городскими материальными объектами и с другими людьми. Ориентация основана на определенных физических возможностях распознавания незрячими людьми, их установках в отношении города и горожан, наборе фиксированных ориентиров и допущении об изменчивости городской среды. Именно интерактивный и ситуативный характер ориентации и передвижения незрячих горожан сегодня не учитывается программами изменения городской среды. В заключение мы предлагаем способы преодоления имеющихся программных ограничений, основанные на выявленных в исследовании способах ориентации и передвижения незрячих горожан.

\section{Ориентация незрячего человека в городе: перспектива феноменологии и этнометодологии}

(Не)доступность города в городских исследованиях традиционно описывается с помощью концепта «право на город» (Харви 2008; Mitchell 
2003). Позволяя обозначить конфликтующие стороны-тех, кто присваивает право пользования городской средой, и тех, кто лишается такой возможности,- этот подход не предлагает концептуального аппарата для описания лежащего в основе противостояния индивидуального опыта конструирования доступности среды. Таким образом, в исследовании нам было необходимо использовать микроаналитическую, «конкретизирующую» рамку феноменологии и этнометодологии (Korbut 2018: 15).

Отправной точкой нашего анализа станет тело незрячего человека, перемещающегося в городской среде. Вслед за Морисом Мерло-Понти, мы определяем тело как «ось мира», основу любого чувствования и осознания, инструмент взаимодействия с миром (Мерло-Понти 1999: 321). Такое понимание выводит тело за границы плоти, допуская наличие чувствующих расширений, одним из которых является трость слепого человека. В феноменологии Мерло-Понти важна материальность тела, определяемого как «вещь, в которой я живу» (там же: 88). Именно она позволяет человеку устанавливать связь с другими вещами (объектами и людьми) и образовывать «феноменальное поле»- ситуативно ограниченную область вокруг тела, в которой обнаруживаются данные в чувственном опыте объекты и феномены (там же:95). Обнаруживаемые в феноменальном поле объекты и люди имеют значение в контексте осуществляемой практики, вплетаясь в систему отношений между индивидом, его действием и прочими вещами и людьми.

Таким образом, объекты и люди, возникающие в феноменальном поле перемещающегося человека, способны сигнализировать о правильности совершаемых им действий. В этом смысле они, согласно терминологии Гарольда Гарфинкеля, являются «ориентированными объектами» (Garfinkel 2002: 179-181). Неспособность соотнести объект с практикой или отсутствие достаточного количества ориентированных объектов приводит к нарушению в исполнении практики. Такие локальные нарушения будут рассмотрены нами как проблемные ситуации, определяющие труднодоступность городского пространства. Отметим, что как покажет эмпирический анализ, ориентированные объекты не обязательно представляют собой материальные объекты или людей, в их качестве могут выступать специфические звуки, запахи или связанные с ними аффекты, такие, как достоверное или ложное предчувствие объекта. Несмотря на то, что ориентация носит сугубо ситуативный характер, она связана с подготовкой и использованием сопровождающих и частично предопределяющих практику дискурсивных артефактов (карт или планов). Такие планы являются «ресурсами ситуативного действия», постоянно сопровождая его, но не предопределяя полностью (Сачмен 2019: 122).

Заявленная рамка не предполагает наличия строгой операционализации, являясь скорее каркасом для описания телесно воплощённой и ситуативно упорядоченной практики. Используемые нами понятия выполняют роль «сенсибилизирующих концептов» (sensitizing concepts), стимулиру- 
ющих эмпирическую чувствительность и задающих общее направление анализа, вместо предопределения исследуемого феномена в виде «чётких определений в терминах атрибутов или фиксированных контрольных отметок» (Blumer 1954: 7). Сохранение концептуальной гибкости важно в силу ограниченной информации о передвижениях и ориентировании незрячих людей в крупных городах, включая российские.

\section{Практики ориентации незрячих людей в городском пространстве}

Статья основана на исследовании, проведенном в 2020-2021 гг., включавшем десять интервью с незрячими людьми в возрасте от 22 до 64 лет, трое из которых мужчины и семеро женщины. Каждый из информантов имел продолжительный опыт утраты зрения (минимум 19 лет). Под «незрячими» в данном исследовании понимались люди с остротой зрения до 6\%, что соответствовало второй группе инвалидности. Этот критерий был выработан в ходе бесед с информантами, определившими такую остроту зрения как предел возможности опираться на него в перемещениях по городу. Все информанты имели опыт ориентации и навигации в пределах Москвы в течение, как минимум, последних четырех лет. Основным методом сбора данных стало полуструктурированное интервью. Выбор интервью позволил нам сохранить гибкость и получить информацию о практиках освоения маршрута, включая апелляции к планам, и рефлексию общей проблемности городского опыта. Стоит признать, что отсутствие типичного для этнометодологического подхода наблюдения за практиками, накладывает ограничения на полноту и подробность описания практик ориентирования. Все имена, использованные в тексте, являются псевдонимами.

Ориентация как процесс, в котором незрячие горожане задействуют разные навыки и комбинируют несколько способов действий, редко становится предметом изучения (Williams et al. 2013). Основное внимание аналитиков сосредоточено на конкретных способах перемещения, таких как, передвижение с помощью GPS (Kuriakose et al. 2020), с собакой-поводырем (Lloyd et al. 2008; Craigon et al. 2017) или ультразвуковой тростью (Sen et al. 2018). Подобный аналитический выбор переводит внимание на вспомогательные технологии или животных-ассистентов, тем самым уменьшая агентность незрячих горожан. Сосредотачиваясь в своей статье на телесном опыте ориентации незрячих горожан, мы хотели бы подчеркнуть их агентость, понимаемую как способность самостоятельно ориентироваться и передвигаться в городской среде, строить маршруты, вырабатывать и комбинировать способы перемещения по городу. Агентность незрячих горожан не является константой: она вырабатывается в повседневных практиках и взаимодействиях с другими горожанами и институциями, которые могут как усиливать, так и ослаблять или лишать ее. 
Рассказывая о своих повседневных маршрутах, информанты упоминали различные навыки ориентации, связанные со считыванием и моделированием пространства при помощи тактильной, вестибулярной и звуковой чувствительности, светоощущения, обоняния и интуиции, научение которым происходило самостоятельно или при помощи специалистов, нередко в специальных учреждениях.

Первым способом ориентации в городе является тактильное считывание пространства, когда незрячий человек касается окружающих объектов специальной тростью или частями тела и использует эту информацию для составления маршрута. Пользуясь тростью, незрячий человек совершает поступательные движения, очерчивая пространство впереди себя-с отрывом трости от поверхности или без, в зависимости от подвижности наконечника. Информанты описывали подобный способ использования трости как конвенционально правильный- именно ему обучают на специализированных курсах по ориентированию в пространстве. Однако реальная практика использования трости может варьироваться, поскольку часто специальное обучение оказывается недоступным и незрячие горожане учатся пользоваться тростью самостоятельно. Так, одна из информанток вспоминала, что вначале она иногда вела трость не впереди себя, а за собой, при этом не совершая поступательных движений, а просто следуя линии бордюра:

У меня ещё были пробежки по прямой, от одного магазина до другого- трость вела не спереди, а сзади, это конечно не очень правильный бег, но ... побегать по прямой, мне это нравилось ... я вдоль бордюра бежала, соответственно, трость была возле бордюра, а я бежала впереди, и могла контролировать по бордюру траекторию (Анастасия).

Трость позволяет незрячему чувствовать границу между различными частями улицы- например между пешеходной и проезжей частью, или между тротуаром и газоном. Граница может определяться через разницу в высоте разных частей дороги или через разницу покрытия, включая специальную тактильную плитку, дающую различную фоновую вибрацию на трость:

Обычно они как расположены- какая-то дорожка, и, например, справа газон. И просто ты идёшь по дорожке, ну, как я делаю, я просто тростью захожу то на газон, то с него. Чуть-чуть, туда-сюда. То же самое по бордюру (Егор).

Понимание границ между частями улицы создаёт представление о перспективе и сменах направления улицы. Кроме фоновых различий в вибрации, трость позволяет различать объекты, находящиеся на пути идущего. Различение объекта связано с резким изменением фонового уровня вибрации- прерывания её резким ударом, или исчезновением вибрации из-за столкновения с пустотой: «Мы ориентируемся, вот, мусорница какая-то, врезался в нее, вот и замечательно, значит, через какое-то время 
нужно поворачивать ... или столбики, которые не позволяют машинам въезжать на тротуары. Вот это очень удобно» (Геннадий). Такое столкновение с объектом служит знаком для смены траектории движения и корректировки маршрута или для локальной корректировки в рамках заданной траектории:

Идешь-идешь, раз, тебе попадается машина, потом идешь, у тебя есть участок, где настежь открыта дверь в магазине, у которой все время стоят грузовики, в которые грузят продукты, и ты идешь и врезаешься в эту дверь или грузовик. Нужно его обойти (Мария).

Аналогичным образом в практику тактильного ориентирования встраиваются объекты меньшего размера, расположенные обычно в закрытых помещениях и воспринимаемые с помощью прикосновений рук. Например, выполненные шрифтом Брайля указатели или прочие элементы. Так, описывая маршруты внутри университета, одна из информанток рассказала о доске с прикрепленными на ней объявлениями как об ориентире по дороге к аудитории: «На четвертом этаже, чтобы дойти до преподавательской, можно коснуться гвоздей, которые там висят с бумажками» (Анастасия).

Вторым способом ориентирования в пространстве является вестибулярная чувствительность. Вестибулярные ориентиры состоят из рефлексии незрячим человеком своих ощущений, вызванных сменой направления, наклоном поверхности или резкими перепадами высот. Так, знаком окончания маршрута может стать замеченное информантом углубление в тротуаре: «Потом, когда бордюр заканчивался, там было такое небольшое углубление, которое я ногами чувствовала, бежала обратно» (Анастасия). Вестибулярные ориентиры могут свидетельствовать как о правильности, так и об ошибочности направления, в котором двигается незрячий человек. Например, увеличенное расстояние между платформой и выходом из вагона электрички означает, что информант пропустил нужную ему станцию.

Третий способ ориентирования в пространстве связан с навыком, названным информантами «эхолокация». Эхолокация предполагает чувствительность к аудиальной среде города. Используя ее, незрячие люди составляют представление об окружающем пространстве, основываясь на расположении и специфике раздающихся в нём звуков. Незрячие горожане могут ориентироваться как на особый аудиальный фон, присущий определенным локациям, например, шум дороги или гул электростанции, так и на отдельные звуки, включая созданные в рамках программы адаптации города аудиальные сигналы светофоров. В частности, ориентиром могут служить различные музыкальные жанры, играющие в расположенных на пути магазинах: «Музыка в ЦУМе играет, там обычно джаз какой-то, а дальше какие-то магазинчики, там обычно классическая музыка, чаще всего Чайковский играл» (Геннадий). 
К ориентирующим фоновым характеристикам можно отнести разницу акустики в различных помещениях или между помещением и открытым пространством. Эхолокация оказывается особенно полезным инструментом для оценки перспективы и направления движения. По сравнению с другими модальностями, например тактильной, слух позволяет незрячим пешеходам ориентироваться на больших расстояниях. Потоки людей и машин, перемещающиеся параллельно с идущим незрячим, неизбежно оставляют аудиальный след, повторяющий контуры, направления и повороты улиц и прочих маршрутов. Таким образом, предстоящий поворот можно услышать быстрее по звуку проезжающих и заворачивающих машин, или проходящих людей, чем почувствовать тростью. Помимо звуков, которыми наполнена окружающая среда, ориентирующим может быть отражение звука, издаваемого самим идущим. Такой способ ориентации особенно эффективно помогает в закрытых пространствах, заменяя тактильное ориентирование:

Я могу щёлкать пальцами и у меня отражается небольшая картинка-вот машина стоит припаркованная, если рядом кусты-я тоже пойму, если рядом забор-я это тоже пойму ... с 5 лет мы с мамой начали называть окружающие предметы, и мама подумала, что мы видим. Но, понятное дело, это невозможно, и врачи сказали, что это не может быть ... Мы ходили на прогулку, мама говорила, давайте посмотрим, что рядоми мы с сестрой называли предметы ... Даже когда в музыкальную школу ездила- там я очень быстро сориентировалась и ходила без трости (Мария).

Наконец, ориентирами для незрячего являются проявления светового и обонятельного ландшафта и «интуиция». Запахи и солнечный свет оказываются мало информативными в процессе ориентации, однако они могут быть полезными, например, свидетельствуя о препятствии, находящемся на пути незрячего: «Я вижу например, что что-то cmoum, но я не вижу человек это или столб, вижу, что тень и надо это обойти» (Екатерина). Незрячие, обладающие остаточным зрением, могут замечать разметку в виде жёлтых линий, обозначающих первую ступеньку, или жёлтых кругов на стеклянных дверях. Аналогичным образом, сигнализировать о правильности направления могут привычные, или, наоборот, нетипичные запахи. Несколько информантов упоминали слабо определяемый, но важный для них способ ориентирования-интуицию, или «шестое чувство» (Геннадий). Говоря о нем, информанты описывали способность определять наличие объектов на пути без объяснимых и понятных самому идущему стимулов: «Слепье иногда препятствия чувствуют непонятно как, создается впечатление, что что-то перед тобой стоит, и ты вот трогаешь это палкой, действительно что-то стоит» (Геннадий).

Практика освоения маршрута связана с запоминанием или «картографированием» наиболее устойчивых объектов среды и их ситуативной верификацией при помощи попеременного включения упомянутых навыков. 
При этом самостоятельная городская навигация незрячего человека серьёзно ограничена. Прежде всего, первое освоение маршрута, как правило, не происходит самостоятельно. Для того, чтобы составить карту маршрута незрячему необходимо несколько раз пройти выбранной дорогой в сопровождении человека с сохранным зрением, или с незрячим человеком, который уже освоил маршрут. Необходимость повторения опыта связана с постепенным освоением объектов, которые могут стать ориентированными. Идущему человеку необходимо время, чтобы выделить ориентирующие объекты, понять их расположение в пространстве и связь друг с другом. Однако даже имея подробное представление о маршруте и объектах, которые помогают в его прохождении, незрячий человек сталкивается с тем, что конфигурация объектов на маршруте может измениться.

\section{Проблемы ориентации: непредсказуемость или недостаточность среды и «слепецкие страхи»}

Несмотря на множество способов ориентации, используемых незрячими людьми, самостоятельность их перемещения по городу серьёзно ограничена трудностями, возникающими в процессе движения. К их числу можно отнести невозможность корректной интерпретации или ошибку интерпретации окружающих объектов, вмешательство в процесс навигации других горожан и страхи, связанные с рисками выхода в город и коммуникацией со зрячими людьми.

Невозможность корректной интерпретации объектов проявляется в ситуациях, когда объекты городской среды расположены или сконструированы таким образом, что не могут быть обнаружены или различены в феноменальном поле незрячего человека. К таким объектам относятся названия остановок и номера общественного транспорта, которые в современном городе представлены исключительно визуально. Особенно проблематичными в данном случае становятся загруженные транспортные узлы, например, вокзалы:

Ощущаю себя запертым примерно в пределах МКАД, потому что история с навигацией по пригородным поездам ... Одно дело сесть в вагон на обычной станции, где всего две платформы- туда и сюда. А другое дело с того же Ярославского вокзала, где 15 путей и десять платформ, найти нужную платформу, нужный путь и сесть на электричку, при том, что дальше там ещё ветки расходятся... Не знаю (Илья).

По этой же причине проблематичным для незрячего горожанина оказывается поиск валидаторов для оплаты проезда, не имеющих унифицированного места в салоне, или поиск нужного выхода из подземных переходов. Неспособность определить нужный объект может обернуться угрозой для жизни незрячего человека. Например, изнашивание или отсутствие тактильной линии, отделяющей платформу метро от рельса, чревато падением: 
Там не было этих полосок, и я улетел на рельсы, ... какие-то ребята там подали мне руку, они, по-моему, испугались больше, чем я ... А вот, когда я сел в поезд, я вот почувствовал и ужас, а с другой стороны, жажда жизни какая-то, знаете, как жизнь возвращается- физически чувствуешь (Геннадий).

Невозможность интерпретации объекта незрячими горожанами может быть связана с чрезмерной сенсорной насыщенностью среды, превращающую ее в неразличимый гул. Например, шум множества автомобилей на оживлённых перекрёстках или некачественно уложенная направляющая тактильная плитка:

Вот эта вот жёлтая рельефная байда, у нас её многие не любят ... Несмотря на то, что существуют стандарты по её укладке, эти полоски должны направлять куда идти, их кладут как попало. ... так, что они слишком сильно выпирают, и трость в них просто втыкается (Илья).

Вторая трудность ориентации- ошибочная интерпретация, в основе которой лежат частичная недоступность объекта для восприятия или недостоверная информация, получаемая от среды. Примером ошибочной интерпретации может служить столкновение незрячего человека с объектом, отличающимся в габаритах у основания, где его можно опознать тростью, и на уровне глаз, таким как таксофон, дорожный указатель или рекламный постер. Ошибка интерпретации, связанная с недостоверностью информации, появляется, когда направляющая городская инфраструктура даёт сбой, как это происходит в случае с неправильным объявлением остановок в общественном транспорте или дезориентирующей укладкой специальной тактильной плитки, ведущей в тупик.

Третья трудность связана с вмешательством посторонних людей в процесс ориентации незрячего горожанина. Такое вмешательство может касаться отдельного человека или устройства какого-то фрагмента городской среды. В первом случае незрячему приходится сталкиваться с неподобающим отношением прохожих - с неуместной помощью или опасным поведением. Например, информанты рассказывали нам о ситуациях, когда посторонние люди пытались без спроса изменить их маршрут: «Люди иногда перебарщцвают и ведут, не спрашивая куда, я уже к этому привыкла ... Конечно, это меня всегда немножко впечатляет, но, если тебя уже несут, ты не очень протестуешь, потому что боишься, что тебя уронят» (Елизавета). Примерами неподобающего отношения являются также угрозы и попытки ограбить незрячего человека, или же, наоборот, чрезмерная забота, проявляющаяся в желании дать милостыню. Во втором случае вмешательство, затрудняющее ориентацию незрячего человека, касается изменения отдельных составляющих городской среды. В частности, в одном из интервью речь шла о демонтаже светофора со звуковым сигналом, причиной которого стала коллективная жалоба жителей района на мешающий им звук. 
Столкновение незрячих людей в их повседневном перемещении по городу со множеством проблем приводит к развитию страхов, препятствующих выходу в город и его освоению. Совокупность таких опасений, или, как назвал их один из информантов «слепецкие страхи», способны затруднять или вовсе останавливать незрячих людей от попыток самостоятельно выйти в город. Кроме самих незрячих, этим же страхам подвержены заботящиеся о них - родственники или преподаватели в интернатах, которые стремятся оградить своих подопечных от самостоятельных перемещений. Как отмечали сами информанты, подобные страхи особенно сильны при отсутствии личного опыта выхода в город и общения со зрячими людьми вне семьи или специальных образовательных учреждений.

\section{Заключение}

Вернёмся к сформулированной в начале работы проблеме ограниченной действенности мер адаптации городской среды. Несмотря на то, что принятие соответствующих мер является важным шагом в борьбе за права людей с инвалидностью, они не являются гарантом создания среды, соответствующей запросам незрячих горожан. Во-первых, введённые в рамках адаптации городской среды дополнительные ориентиры нередко подчиняются логике восприятия пространства зрячим человеком и не доступны незрячим людям без посторонней помощи, что воспроизводит окулоцентрическую логику организации городской жизни. Ярким примером непонимания особенностей восприятия города незрячими людьми является автобусный парк, оценка доступности которого, согласно официальной отчётности, составляет 94\%. Однако ни один из автобусов в Москве не оснащён каким-либо способом обозначения номера маршрута, доступного снаружи автобуса, кроме информационного табло (ДЭПиР 2018: 44). Также незрячим людям без посредников невозможно воспользоваться специально создаваемыми для них инфраструктурными возможностями, например, отдельными местами для незрячих с собаками-поводырями, выделенными в некоторых автобусах. Такие места отмечены только стикером, который незрячий пассажир не сможет обнаружить без посторонней помощи.

Во-вторых, качество реализации заявленных мер в ряде случаев отличается от декларируемого городскими властями, как это происходит в случае появления тактильных поверхностей ненадлежащего качества или не ориентирующих людей в пространстве. В-третьих, сама политика создания доступной среды ориентирована на внесение стабильных изменений - создание соответствующей инфраструктуры (светофоров со звуковым сигналом, тактильной плитки, надписей шрифтом Брайля и др.), однако эти объекты могут утрачивать свою функциональность из-за изменчивости городской жизни, связанной с сезонностью, ремонтными работами, старением и изнашиваемостью материалов, враждебными 
действиями горожан. В-четвертых, программы создания доступной среды основаны на представлении о полезности изменений для всех горожан и их однозначной поддержке, что является заблуждением. Адаптация среды для определенных групп, может затруднять ее использование другими горожанами, как например тактильная плитка может вносить дискомфорт в передвижение горожан с багажом или колясками.

Наряду с критикой реализуемых мер, незрячие горожане выделяют и позитивные изменения, облегчающие их ориентацию в городе, такие как создание служб сопровождения мобильности и светофоров со звуковым сигналом. Однако эти меры радикально не меняют ситуацию, концентрируясь в определенных городских пространствах. Ограниченность мер создает дискретный раздробленный город, в котором одни и те же пространства могут работать и как инклюзивные, и как исключающие. Эта дискретность и противоречивость особенно заметна в общественном транспорте, где, с одной стороны, создается служба сопровождения и другие условия для передвижения незрячих горожан, с другой стороны, на уровне знаковых систем (и их обновления) не поддерживается способность незрячих людей к самостоятельной ориентации.

Указанные недостатки не означают бесполезность предпринимаемых мер, но указывают на возможные способы их совершенствования. Такие меры, как привлечение незрячих людей к тестированию и разработке ркомендаций по увеличению доступности городской среды, информирование незрячих людей об уже осуществленных преобразованиях, увеличение уровня осведомлённости зрячих людей об особых потребностях незрячих людей, их способностях самостоятельно передвигаться и способах помощи им могли бы значительно облегчить повседневные перемещения незрячих горожан. Кроме того, незрячим людям важно иметь возможность получить помощь в преодолении страхов и недоверия городской среде и другим горожанам через создание положительного опыта нахождения в городе.

\section{Список источников}

Wylsacom (2018) Как незрячий пользуется iPhone, MacBook и Apple Watch. Доступно по ссылке: https://www.youtube.com/watch?v=RQiN1Hhrxu0 (дата обращения: 21 октября 2021).

ДЭПиР г. Москвы (2018) Свободный отчёт о результатах проведения оценки фактического воздействия постановления Правительства Москвы от 16.03.2010 № 219-ПП «О мерах по обеспечению беспрепятственного доступа инвалидов и иных маломобильных граждан к объектам соииальной, транспортной и инженерной инфраструктур города Москвы». Доступно по ссылке: https://www.mos.ru/upload/documents/files/3450/SvodniiotchetorezyltatahOFVPPM219-PP.pdf (дата обращения: 21 октября 2021).

Клепикова А. (2015) Социальные исследования инвалидности на постсоветском пространстве. Антропологический форум, (26): 222-244.

Мерло-Понти М. (1999) Феноменология восприятия. М.: Ювента. 
Наберушкина Э. (2011) Город для всех: социологический анализ доступности городского пространства для инвалидов. Журнал сочиологии и сочиальной антропологии, 14 (3): 119-139.

Сачмен Л. (2019) Реконфигурации отнотений человек-машина: планы и ситуативные действия. М.: Элементарные формы.

Сеннет Р. (2016) Плоть и камень. Тело и город в западной ичивилизации. M.: Strelka Press.

Сталингулаг (2019) На колёсах с Артемием Лебедевым. По иентру Москвы на инвалидной коляске. Доступно по ссылке: https://www.youtube.com/watch?v=waKndLPoHxk (дата обращения: 21 октября 2021).

Филлипс С. (2018) Параллельный мир. А. Курленкова, Е. Носенко-Штейн (ред.) Обратная сторона Луны, или что мы не знаем об инвалидности: теория, репрезентации, практики. М.: МБА:223-273.

Харви Д. (2008) Право на город. Логос, 3 (66): 80-94.

Ярская-Смирнова Е., Романов П. (2010) Инвалидность и общество: двадцать лет спустя. Соииологические исследования, (9): 50-58.

Blumer H. (1954) What is wrong with social theory? American sociological review, 19 (1):3-10. Charlton J. (1998) Nothing about Us without Us. California: University of California Press.

Craigon P., Hobson-West P., England C., Whelan C., Lethbridge E., Asher L. (2017) 'She's a Dog at the End of the Day': Guide Dog Owners' Perspectives on the Behaviour of Their Guide Dog. PLoS ONE, 12(4): e0176018. https://doi.org/10.1371/journal.pone.0176018.

Ferguson P., Nusbaum E. (2012) Disability Studies: What is It and What Difference Does It Make? Research and Practice for Persons with Severe Disabilities, 37 (2): 70-80.

Garfinkel H. (2002) Ethnomethodology's Program: Working out Durkheim's Aphorism. Lanham: Rowman \& Littlefield.

Goodley D. (2017) Disability Studies: An Interdisciplinary Introduction. London: Sage.

Kalyukin A., Borén T., Byerley A. (2015) The Second Generation of Post-Socialist Change: Gorky Park and Public Space in Moscow. Urban Geography, 36 (5): 674-695.

Korbut A. (2018) The Social Order and Practical Wisdom of Walking in a Crowd. Sociological Journal, (4): 8-29.

Kuriakose B., Shrestha R., Sandnes F.E. (2020) Smartphone Navigation Support for Blind and Visually Impaired People - A Comprehensive Analysis of Potentials and Opportunities. In: M. Antona, C. Stephanidis (eds.) Universal Access in Human-Computer Interaction. Applications and Practice. Cham: Springer: 568-583.

Lloyd J., Grow S., Stafford K., Budge C. (2008) The Guide Dog as a Mobility Aid Part 1: Perceived Effectiveness on Travel Performance. International Journal of Orientation \& Mobility, (1): 17-33.

Mitchell D. (2003) The Right to the City: Social Justice and the Fight for Public Space. New York: Guilford press.

Neuschmid J., Gajevic L., Schrenk M., Wasserburger W. (2014) The Blind's Critical Space and the Role of Modern ICT. In: A. Calcatinge (ed.) Critical Spaces: Contemporary Perspectives in Urban, Spatial and Landscape Studies. Münster: LIT Verlag: 179-203.

Sen A., Sen K., Das J. (2018) Ultrasonic Blind Stick for Completely Blind People to Avoid Any Kind of Obstacles. 2018 IEEE SENSORS, New-Delhi, 28 October 2018. (Piscataway: Institute of Electrical and Electronics Engineers).

Williams M., Hurst A., Kane S. (2013) 'Pray before You Step Out': Describing Personal and Situational Blind Navigation Behaviors. 15th International ACM SIGACCESS Conference on Computers and Accessibility (ASSETS '13), Bellevue, 21 October 2013. Доступно по ссылке: http://dx.doi.org/10.1145/2513383.2513449 (дата обращения: 21 октября 2021). 
Viktor Sinitsyn, Oksana Zaporozhets

\title{
PRACTICES OF ORIENTATION AND INDEPENDENT EVERYDAY MOBILITY OF VISUALLY IMPAIRED URBAN CITIZENS
}

\begin{abstract}
This year will mark the 10th anniversary of the 'Accessible environment' state programme in Russia. Following the UN Convention on the Rights of Persons with Disabilities, the programme aimed at overcoming the social exclusion of people with disabilities in daily urban life. However, despite broad implementation of measures, the accessibility of Russian cities is evaluated controversially. While official reports note the increasing number of accessible objects, experts and people with disabilities express concerns over the lack of significant changes. This article highlights some reasons for this. Using phenomenology and ethnomethodology as an analytical framework, we expose the basic practices of orientation and creating day-to-day routes for visually impaired Muscovites, as well as barriers restricting their independent mobility in an urban environment. According to our research, the orientation of visually impaired citizens is based on the tactile, vestibular, light, olfactory, auditory, or intuitive sensitivities that help them in the selection, mapping and situational verification of the route's most stable landmarks. Independence in accomplishing routes is hampered by a lack of accessible landmarks or their own misinterpretations caused by either structural features or the situational conditions of the environment. In addition to barriers in navigating the city, other issues include the fear of going outdoors and navigating the city as well as the possibility that other citizens will interference their travel. Our study shows that the 'Accessible environment' programme aims to change the city's materiality to make it more navigable for visually impaired people. Meanwhile, their orientation and navigation depend on various skills and conditions, including the ability to interpret the environment, their attitudes towards others and the urban environment, and practices of communication.
\end{abstract}

Key words: visually impaired, disability, accessibility, orientation, city, phenomenology, qualitative sociology

DOI: 10.17323/727-0634-2021-19-4-669-684

\section{References}

Blumer H. (1954) What is Wrong with Social Theory? American sociological review, 19 (1): $3-10$.

Charlton J. (1998) Nothing about Us without Us. California: University of California Press.

Viktor Sinitsyn- MSc in Social sciences, Research Assistant, Laboratory of Urban Sociology, HSE University, Moscow, Russian Federation. Email: viktor.sinitsyn@gmail.com

Oksana Zaporozhets - Cand. Sci. (Sociol.), Associate Professor, Faculty of Urban and Regional Development, National Research University Higher School of Economics, Moscow, Russian Federation. Email: ozaporozhets@hse.ru 
Craigon P., Hobson-West P., England C., Whelan C., Lethbridge E., Asher L. (2017) 'She's a Dog at the End of the Day': Guide Dog Owners' Perspectives on the Behaviour of Their Guide Dog. PLoS ONE, 12 (4): e0176018. https://doi.org/10.1371/journal.pone.0176018.

$\mathrm{DEPaD}$ of Moscow (2018) Svobodnyy otchet o rezul'tatakh provedeniya otsenki fakticheskogo vozdeystviya postanovleniya Pravitel'stva Moskvy ot 16.03.2010 No 219-PP 'O merakh po obespecheniyu besprepyatstvennogo dostupa invalidov i inykh malomobil'nykh grazhdan k ob"ektam sotsial 'noy, transportnoy i inzhenernoy infrastruktur goroda Moskvy' [Free Report on Evaluation of an Actual Impact of Moscow Government's Decree No 219Pp 'On Measures to Ensure Unhindered Access of Disabled People and Other People with Limited Mobility to Social, Transport and Engineering Infrastructures of the City of Moscow']. Available at: https://www.mos.ru/upload/documents/files/3450/SvodniiotchetorezyltatahOFVPPM219-PP.pdf (access 21 October 2021).

Ferguson P., Nusbaum E. (2012) Disability Studies: What is it and What Difference Does It Make? Research and Practice for Persons with Severe Disabilities, 37 (2): 70-80.

Garfinkel H. (2002) Ethnomethodology's Program: Working out Durkheim's Aphorism. Lanham: Rowman \& Littlefield.

Goodley D. (2017) Disability Studies: An Interdisciplinary Introduction. London: Sage.

Harvey D. (2008) Pravo na gorod [The Right to the City]. Logos, 3 (66): 80-94.

Kalyukin A., Borén T., Byerley A. (2015) The Second Generation of Post-Socialist Change: Gorky Park and Public Space in Moscow. Urban Geography, 36 (5): 674-695.

Klepikova A. (2015) Sotsial'nye issledovaniya invalidnosti na postsovetskom prostranstve [Social Studies of Disability in Post-Soviet Countries]. Antropologicheskiy forum [Forum for Anthropology and Culture], (26):222-244.

Korbut A. (2018) The Social Order and Practical Wisdom of Walking in a Crowd. Sociological Journal, (4): 8-29.

Kuriakose B., Shrestha R., Sandnes F.E. (2020) Smartphone Navigation Support for Blind and Visually Impaired People - A Comprehensive Analysis of Potentials and Opportunities. In: M. Antona, C. Stephanidis (eds.) Universal Access in Human-Computer Interaction. Applications and Practice. Cham: Springer: 568-583.

Lloyd J., Grow S., Stafford K., Budge C. (2008) The Guide Dog as a Mobility Aid Part 1: Perceived Effectiveness on Travel Performance. International Journal of Orientation \& Mobility, (1): 17-33.

Merlau-Ponty M. (1999) Fenomenologiya vospriyatiya [Phenomenology of Perception]. Moscow: Uwenta.

Mitchell D. (2003) The Right to the City: Social Justice and the Fight for Public Space. New York: Guilford press.

Naberushkina E. (2011) Gorod dlya vsekh: sotsiologicheskiy analiz dostupnosti gorodskogo prostranstva dlya invalidov [A City for Everyone: Sociological Analysis of the Accessibility of Urban Environment for People with Disabilities]. Zhurnal sotsiologii i sotsial'noy antropologii [Journal of sociology and social anthropology], 14 (3): 119-139.

Neuschmid J., Gajevic L., Schrenk M., Wasserburger W. (2014) The Blind's Critical Space and the Role of Modern ICT. In: A. Calcatinge (ed.) Critical Spaces: Contemporary Perspectives in Urban, Spatial and Landscape Studies. Münster: LIT Verlag: 179-203. 
Phillips S. (2018) Parallel'nyy mir [Parallel World]. In: A. Kurlenkova, E. Nosenko-Stein (eds.) Obratnaya storona Luny, ili chto my ne znaem ob invalidnosti: teoriya, reprezentatsii, praktiki [The Other Side of the Moon, or What We Don't Know about Disability: Theory, Representations, Practices]. Moscow: MBA publishers: 223-273.

Scott J. (2005) Seeing Like a State: How Certain Schemes to Improve the Human Condition Have Failed. Moscow: University book.

Sen A., Sen K., Das J. (2018) Ultrasonic Blind Stick for Completely Blind People to Avoid Any Kind of Obstacles. 2018 IEEE SENSORS, New-Delhi, 28 October 2018. (Piscataway: Institute of Electrical and Electronics Engineers).

Sennett R. (2016) Flesh and Stone: The Body and the City in Western Civilization. Moscow: Strelka Press.

Stalingulag (2019) On Wheels with Artemy Lebedev. Through the Center of Moscow on a Wheelchair. Available at: https://www.youtube.com/watch?v=waKndLPoHxk (access 21 October 2021).

Suchmen L. (2019) Rekonfiguratsii otnosheniy chelovek- mashina: plany i situativnye deystviya [Human-machine Reconfigurations: Plans and Situated Actions]. Moscow: Elementary forms press.

Williams M., Hurst A., Kane S. (2013) 'Pray before You Step Out': Describing Personal and Situational Blind Navigation Behaviors. 15th International ACM SIGACCESS Conference on Computers and Accessibility (ASSETS '13), Bellevue, 21 October 2013. Available at: http://dx.doi.org/10.1145/2513383.2513449 (accessed 21 October 2021).

Wylsacom (2018) Kak nezryachiy pol'zuetsya iPhone, MacBook i Apple Watch [How Does a Blind Person Use iPhone, MacBook and Apple Watch]. Available at: https://www.youtube.com/watch? v=RQiN 1Hhrxu0 (accessed 21 October 2021).

Yarskaya-Smirnova E., Romanov P. (2010) Invalidnost' i obshchestvo: dvadtsat' let spustya [People with Disabilities and Society: Twenty Years Later]. Sotsiologicheskie Issledovaniia [Sociological Studies], (9): 50-58. 